\title{
Discursos do nacional no romance brasileiro contemporâneo: Dois irmãos e Cidade de Deus
}

\author{
Anderson Luís Nunes da Mata ${ }^{1}$
}

As relações entre a gênese do romance moderno e dos Estados nacionais já foram exploradas em muitos textos historiográficos tornados célebres no âmbito da crítica e da teoria da literatura (EAgleton, 2003, p. 24-30; Sommer, 2004, p. 48). Essa gênese diretamente relacionada a um projeto político de consolidação de línguas, e, por consequência, de Estados nacionais, é normalmente localizada nos séculos XVII e XVIII, na Europa e, na segunda metade do século XIX, na América Latina. Ao longo do século XX, contudo, a crítica literária consagrou espaço privilegiado para a discussão das relações entre a literatura e a nação (MATA, 2010a, p. 47). Esse espaço gerou, em princípios do século XXI, uma reação mais declarada de autores que rejeitaram as amarras às questões do nacional, buscando outras saídas e discussões em seus textos. Romancistas como Elvira Vigna e Bernardo Carvalho, por exemplo, investiram na escrita de romances como Coisas que os homens não entendem e Teatro (MATA, 2012, p. 17), que, se não abandonam a circunscrição à temática do nacional, investem contra a ideia de uma nação como definidora das identidades étnicas e linguísticas de seus protagonistas e dos espaços pelos quais eles transitam.

Portanto, esse investimento de valorização dos problemas relativos à representação do nacional na literatura, e, de modo acentuado, no romance brasileiro, feito pela crítica literária ao longo dos séculos XIX e xx ainda encontra ressonância na produção literária de autores surgidos no entorno do século XxI.

Milton Hatoum e Paulo Lins, dois autores que, cada um a sua maneira, encontraram, ao longo dos anos 1990 e 2000, espaço de interlocução na crítica literária e público leitor de suas obras, abordam, ora explicitamente, ora a contrapelo, a discussão do nacional, preocupando-se com o problema do que fazer com legado de uma tradição formal, linguística e cultural.

1 Doutor em literatura e professor da Universidade de Brasília (UnB), Brasília, Distrito Federal, Brasil. E-mail: amata@unb.br 


\section{O nacional a contrapelo: o ponto de vista periférico}

Em Dois irmãos, de Milton Hatoum, o tema do nacional emerge pela via do estranhamento. Inicialmente, há o estranhamento com o espaço da narrativa: uma Manaus após a Segunda Guerra Mundial habitada por imigrantes libaneses e seus descendentes. Tradicionalmente identificado como um espaço estereotípico de uma brasilidade nativa e selvagem, Manaus aqui é lugar de uma imigração que costumamos identificar com os grandes centros metropolitanos brasileiros. O ostracismo em que entrou a cidade após o ciclo da borracha, cujos efeitos da derrocada são justamente tratados no tempo histórico-social do romance, distancia o leitor de fora desse cosmopolitanismo vivido pela região na primeira metade do século xx. Isso se deve também ao insulamento de Manaus no espaço geográfico brasileiro - capital a que não chegam as grandes rodovias que foram o cerne do projeto moderno de integração nacional. Assim, a Manaus cosmopolita de Dois irmãos é uma cidade que se apresenta como estranha para quem se habituou a enxergá-la como um espaço de urbanismo subdesenvolvido e de natureza exuberante. É um olhar de dentro que provoca um distúrbio numa das paisagens muito exploradas pelo nacionalismo brasileiro e mais representativas do nacional.

Outra via para o estranhamento provocado no romance está no modo como um de seus protagonistas, Yaqub, um dos irmãos do título do livro, reage a uma temporada fora do país. O romance é aberto com a volta de Yaqub de uma passagem pelo Líbano, país de origem de seus pais. Nesse retorno, o narrador nos apresenta a seguinte cena: "Yaqub abriu o farnel e tirou um embrulho, e o pai viu os pães embolorados e uma caixa de figos secos. Só isso trouxera do Líbano? Nenhuma carta? Nenhum presente?" (НАтоum, 20oo, p. 14). Yaqub parece não trazer lembranças concretas do Líbano e seu estranhamento maior será reaprender os códigos linguísticos, sociais e científicos da comunidade manauara. A mãe teme que o filho não se readapte: "Meu filho vai voltar um matuto, um pastor, um raï. Vai esquecer o português e não vai pisar na escola porque não tem escola lá na aldeia da tua família" (HAтоuм, 200o, p. 15), ela reclama com o marido. De fato, “a separação fizera Yaqub esquecer certas palavras da língua portuguesa. Ele falava pouco, pronunciando monossílabos ou frases curtas; calava quando podia, e, às vezes, quando não devia" (HATOuM, 200o, p. 16). Há, no retorno de Yaqub, no entanto, uma forte identificação que faz com que a memória se coloque em operação: "As palavras, a sintaxe, 
a melodia da língua, tudo parecia ressurgir" (Hatoum, 200o, p. 23). É um reconhecimento imediato de sua comunidade, do lugar onde pode sentir-se à vontade.

A ideia de pertencimento é fundamental para compreender o personagem de Yaqub. Seu retorno, apesar de marcado pelo reconhecimento de uma cultura que guardava na memória, não garante que ele consiga se estabelecer em Manaus confortavelmente. Por não ser o sujeito cosmopolita que se sente em casa em qualquer lugar, há um desconforto no lugar onde ele se encontra. Yaqub logo decide partir para um centro metropolitano do país e deixa a cidade decadente para trás. É interessante notar que a derrocada do ciclo da borracha, marcada pela Segunda Guerra Mundial, determina a ruptura de Yaqub, e de seu irmão gêmeo, Omar, com a infância. Tanto Yaqub quanto Omar deixam de encontrar lugar nessa Manaus transfigurada pela pobreza crescente: uma pobreza que se expande para suas existências, do que Yaqub foge indo tentar a vida longe dali, e na qual Omar mergulha vivendo numa boemia autodestrutiva. Assim, ao estranharem-se nesse espaço degradado, os irmãos gêmeos expressam esse desconforto marcado pelo não pertencimento a uma comunidade. Chamo a atenção aqui para o caso de Yaqub porque é ele que traz mais evidentemente o problema da cultura nacional forjada a partir de fluxos migratórios, típica das Américas, que dificultam a delimitação de um nacionalismo elaborado em bases comuns únicas. Para Zana e Halim, os pais de Yaqub e Omar, a família é a primeira comunidade da qual se cobra fidelidade e com a qual se permite a identificação, daí toda a atmosfera incestuosa que marca o afeto da mãe pelos filhos, a relação sensual da irmã, Rania, com os irmãos, e mesmo a tensão homoerótica de disputa entre os irmãos. A partir desse núcleo familiar, as referências culturais se multiplicam e se confundem, indo do Líbano ao centro da floresta amazônica; do meio acadêmico paulista à boemia ribeirinha de Manaus.

O romance, ao chamar atenção para a questão do pertencimento a uma comunidade, elabora a tese de que essa comunidade não é imaginada de forma harmônica sequer dentro de um núcleo simbolicamente tão simbiótico como o de dois irmãos gêmeos. Por outro lado, há uma demanda para que esse imaginário se concretize apaziguado, num esforço que cabe à mãe, à irmã e à criada da família (mãe do narrador, Nael, cujo pai é um dos irmãos que a violentou). 
O poema de Carlos Drummond de Andrade, que serve de epígrafe para o romance, ajuda a elucidar o lugar da família no desenvolvimento da trama do romance e das ligações que ele estabelece entre esse núcleo familiar e a nação.

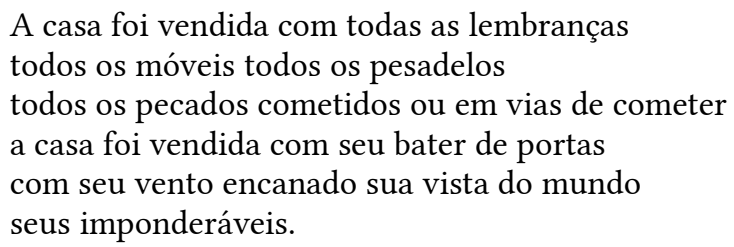

O autor escolhe, desde essa epígrafe, centrar sua atenção na casa, isto é, delimitar o espaço central da narrativa como aquele em que circula a família e que é privativo dela. Não só isso, mas também trata da dissolução desse espaço e de sua memória, vendidos. Nesse sentido, seria arriscado forçar aqui uma leitura de que a casa representaria, de algum modo, um espaço nacional. Por isso, prefiro pensar nessa casa como a imagem de um núcleo que se desfaz, mas cujas ruínas perduram, complexificando esse imaginário do que seria uma nação. Mesmo o projeto literário de Milton Hatoum parece ir nessa direção. Ele escolhe um espaço geográfico específico dentro do mapa de um país com tantas paisagens diferentes. E dentro desse espaço delimita, nos seus três primeiros romances (além de Dois irmãos, Relato de um certo oriente e Cinzas do norte), um núcleo cultural muito específico: o dos imigrantes libaneses. Dentro desse recorte, ele oferece uma espécie de ponto de vista, que é tão mais perturbador quanto menos traz de estereotípico da paisagem amazônica. Não é possível, contudo, negar que o romance Dois irmãos, ao optar por personagens imigrantes e seus descendentes, demonstre preocupação com a compreensão do que é essa nacionalidade miscigenada brasileira, muitas vezes vendida sem que pesadelos e pecados tivessem sido discutidos, mas cuja visão de mundo permanece, ainda que na memória de um narrador que conheceu a história a partir do quarto da criada.

A resistência em trabalhar sobre a tradicional dicotomia Norte/Sul é um ponto importante destacado por Gabriel Albuquerque (2006, p. 138) para compreender o modo como Hatoum empreende seu projeto de escrita sobre a decadência de Manaus a partir do ponto de vista dos libaneses. Para Albuquerque, não há um contraponto da perspectiva dos narradores de Hatoum. 
Nesse sentido, ele não estaria em busca de engendrar um identidade "reconhecível e aceitável para o Brasil culto e rico do Sul/Sudeste" (2006, p. 138).

O romance é arquitetado numa sucessão de descentramentos que vão desde a caracterização do espaço até a escolha do ponto de vista narrativo. Se o discurso é poder, e narrar, um exercício de imposição política, há uma espécie de policentrismo ${ }^{2}$ em operação aqui.

Esse olhar a partir da periferia de uma casa grande também é o modo como Cidade de Deus apresenta-se como uma leitura do nacional. No caso do romance de Paulo Lins, a ligação com o tema aqui em questão é ainda menos direta que nos romances de Carvalho, Vigna e Hatoum. A Cidade de Deus da ficção é um bairro que se agiganta como a visão de mundo de um narrador que tem a ambição, nesse caso, de proporcionar uma leitura alegórica de sua história. É ao mesmo tempo a história de uma comunidade específica e a história de um país que se transforma. A proporção épica que o romance assume deve-se, em primeiro lugar, à ambição do seu recorte temporal (segunda metade dos anos 1960 até meados dos anos 1980), que coincide exatamente com o período do regime militar (1964-1985). A ausência de menções ao ambiente político no romance, a despeito dessa coincidência temporal, é uma ausência que já chama a atenção para a pretensão de Lins de tratar exatamente do que acontecia na periferia dessa grande cidade, e, mais tarde, a crítica viria a encontrar no romance uma potência alegórica que faz de Cidade de Deus um espaço microcósmico de experimentação socioeconômica que ocorria à margem da história oficial.

O status de um outro olhar sobre a história é atribuído ao livro primeiramente em virtude da autoria. Paulo Lins é egresso de Cidade de Deus e, após engajar-se numa pesquisa acadêmica sobre a criminalidade no bairro, escreve o livro, com o apoio de sua coordenadora de pesquisa, Alba Zaluar, da editora Companhia das Letras e com a supervisão de Rubem Fonseca. Todo o aparato montado para que o romance viesse a lume, além do fato de Paulo Lins já ter saído do bairro, faz com que seu olhar seja o de alguém que está a meio caminho dessa periferia. O romance traz um narrador heterodiegético, onisciente, que busca apagar as marcas de sua subjetividade ao longo da narrativa, insinuando-se mais evidentemente apenas na invocação à musa, que aparece logo no princípio do romance.

2 Sobre policentrismo, ver Shohat e Stam (2004, p. 85). 
É nessa invocação que o narrador delimita o escopo do seu trabalho:

Poesia, minha tia, ilumine as certezas dos homens e os tons de minhas palavras. É que arrisco a prosa mesmo com balas atravessando os fonemas. É o verbo, aquele que é maior que o seu tamanho, que diz, faz e acontece. Aqui ele cambaleia baleado. Dito por bocas sem dentes e olhares cariados, nos conchavos de becos, nas decisões de morte. A areia move-se no fundo dos mares. A ausência de sol escurece mesmo as matas. O líquido morango do sorvete mela as mãos. A palavra nasce no pensamento, desprende-se dos lábios adquirindo alma nos ouvidos, e às vezes essa magia sonora não salta à boca porque é engolida a seco. Massacrada no estômago com arroz e feijão a quase palavra é defecada ao invés de falada.

Falha a fala. Fala a bala (Lins, 2003, p. 21).

Aqui, como assinala Adriana Melo, "não há lugar para a inspiração, mas sim para um pouco de ajuda para aquele que não está acostumado a falar, pois não tem armas, está ao lado do oprimido" (Melo, 2009, p. 12). O narrador se posiciona, desse modo, como vítima de um sistema literário que não lhe dá voz. Ele pretende marcar, com uma investida em signos da corporeidade ("bocas sem dentes", "olhares cariados", "palavra defecada") sua diferença em relação àqueles que tradicionalmente dominam o discurso literário. O que chama a atenção é que ele não busca desprender-se dessa tradição, para narrar o romance em si, como veremos mais adiante. Sua introdução ao texto vale, no entanto, como uma apresentação das credenciais de sua experiência de vida, posteriormente confirmada pela crítica que apresentou o livro na imprensa nacional, a resenha de Roberto Schwarz, intitulada "Cidade de Deus”. Ali o crítico literário preocupa-se primeiramente em analisar o romance, como estratégia para não justificar seu tom elogioso pela origem étnico-social do autor do romance. Contudo, ele não deixa de afirmar que

talvez se possa dizer que em Cidade de Deus os resultados de uma pesquisa ampla e muito relevante [...] foram ficcionalizados do ponto de vista de quem era o objeto do estudo, com a correspondente ativação de um ponto de vista de classe diferente (mas sem promoção de ilusões política no capítulo). Significativa em si mesma, essa recombinação de fatores tem um tom próprio, que no conjunto funciona vigorosamente, embora destoando da "prosa bem-feita". Seja como for, a amplitude e o mapeamento da matéria, o ânimo sistematizador e pioneiro, que conferem ao livro peso especial, têm a ver com a vizinhança do trabalho científico e também do trabalho em equipe (ScHWARZ, 2001, p. 168). 
Schwarz assume, nesse trecho, a importância do lugar de fala de Lins como sendo originário da comunidade sobre a qual escreve, ao mesmo tempo que credita a qualidade do romance ao saber produzido pela ciência social. É, então, a partir de um lugar cindido entre sujeito e objeto que Lins escreve seu romance. De alguma forma o narrador, na citada invocação à musa renega esse entrelugar ao declarar-se parte de um polo oposto ao daqueles que se beneficiam da miséria da comunidade. Vale lembrar que essa miséria inclui também a riqueza dos grandes traficantes, que enriquecem sem poder consumir, já que o consumo é vedado a quem é da favela.

Ser da favela é, então, uma forma de identificar-se com um espaço. Não mais uma cultura nacional ou mesmo ancestral, como no caso de Yaqub, mas uma comunidade cujos moradores têm em comum o fato de não pertencerem ao asfalto, isso é, seriam marcados pela classe, sejam trabalhadores ou bandidos. Essa é a tônica dominante em diversas das micronarrativas que compõem o mosaico épico que constitui Cidade de Deus: o menino não consegue emprego se disser que é da favela; o traficante não se sente à vontade para ir comprar as roupas da moda porque é da favela; o trabalhador sofre com o estigma de favelado e luta heroicamente para vencer o crime e mudar o rumo de toda a comunidade.

Cidade de Deus foi um bairro criado para alojar os desabrigados por uma temporada de chuvas fortes no Rio de Janeiro. Ali, pelas mãos do Estado, passaram a pertencer a um espaço que lhes foi entregue e a cuja sorte foram abandonados, fora da nação. Katherine Verdery lembra-nos que o radical etimológico da palavra nação está contido em "nascer", uma "ideia crucial para fazer com que qualquer sistema de categorias pareça natural" (VERDERY apud BALAKRISHNAN, 2000, p. 239). Não há naturalidade no modo como as personagens são deixadas para viverem em comunidade. Além disso, toda a trajetória da ascensão da criminalidade como principal forma de expressão de poder no lugar é narrada de modo a marcar esse afastamento entre o Estado e a comunidade. Ela, no entanto, não tem raízes, ainda que inventadas ou imaginadas, para firmar-se como tal. É por isso que se presta tão bem à alegoria do surgimento de um poder político que prescinde do nacional e que se afirma por um capital ligado ao comércio ilegal de drogas, que já ali se prenuncia como transnacional. 
Cidade de Deus traz, desse modo, a contrapelo da discussão sobre o modo como um gangsterismo de favela se impôs como força política na periferia do Rio de Janeiro, um comentário sobre o lugar da nação nesse espaço degradado que descreve. Dentro da dinâmica social elaborada no romance, a nação enquanto um projeto moderno de integração está do outro lado, no asfalto. É a ausência de um Estado, que acabaria por determinar o lugar de uma noção tradicional de nação nesse espaço, o que mantém o nacional longe das preocupações de personagens como Pardalzinho, Zé Miúdo ou a Caixa-Baixa.

A afirmação, em $O$ silêncio das crianças (MATA, 2010b), de que a tomada do poder na favela pela Caixa-Baixa, um grupo de meninos, simbolizava, no romance, o futuro sombrio do país, uma vez que aquelas crianças tiveram sequestradas suas infâncias, está ancorada na percepção de que ali o significado da infância na narrativa ainda guardava uma forte relação com as principais categorias do romantismo, e, assim, com a ideia de formação de uma nação. O fato de, em Cidade de Deus não haver infância para os "meninos homens de pouca idade" que entram no universo do crime, deixa-os fora dos projetos nacionais que investem em políticas públicas para as crianças, que representam o futuro. A Caixa-Baixa, na sua pulverização do poder nas mãos de várias (e anônimas) crianças, impede mesmo a identificação de um líder, elemento importante para a construção do imaginário da nacionalidade, segundo Anderson (2008). Nesse sentido, o controle do poder insinua-se para uma tessitura em rede, como apontam Hardt e Negri:

Como não tem centro e praticamente qualquer pedaço pode operar como um todo autônomo, a rede pode continuar a funcionar mesmo com parte dela destruída. O elemento central do desenho que assegura a sobrevivência, a descentralização, é o mesmo que torna tão difícil controlar a rede. Este modelo democrático é o que Deleuze e Guattari chamam de rizoma, uma estrutura de rede não hierárquica e não centralizada (HARDT; NEGRI, 2004, p. 320).

Lins dialoga com essa noção de um poder imperial que se espalha como uma rede vazada sobre, e à margem, do poder Estatal, que garantiria a unidade nacional, à qual essa comunidade passa a resistir. No entanto, apesar dessa proposta de ruptura e superação estrutural do nacional, Cidade de Deus presta tributo tanto aos padrões linguísticos do português do Brasil, quanto à tradição romanesca nacional, integrando-se na série literária de modo harmônico, descontada a dissonância da voz marginal de que já tratamos. 


\section{Literatura nacional: um conceito problemático}

As narrativas de Dois irmãos e Cidade de Deus enfrentam, de modo crítico, uma categoria do campo literário que se convenciona chamar "literatura brasileira". O que seria afinal uma literatura nacional? A pergunta é tanto mais relevante num momento em que os próprios narradores recusam a ideia tradicional de nação. Nos termos de Misroslav Hroch, ela é um construto baseado em laços como "a lembrança de um passado comum", "uma densidade de traços linguísticos ou culturais que permitam um grau mais alto de comunicação social dentro do grupo que fora dele"; e "uma concepção que afirme a igualdade de todos os membros do grupo, organizado como uma sociedade civil” (Hroch apud Balakrishnan, 200o, p. 87). Nesse sentido, é difícil falar em literatura nacional sem levar em conta a já muito discutida categoria de sistema literário, de Antonio Candido. ${ }^{3}$ Isto é, o texto insere-se no sistema como parte de uma série literária com a qual dialoga seja em continuidade, seja em ruptura, e se mantém encerrado nessa leitura, na lógica crítica da identificação entre forma literária e forma social. A definição do que seria uma forma social repousa na categoria da nação como um dado apriorístico, isto é, não questionando os pressupostos básicos postulados por Hroch: um imaginário e uma língua compartilhados sob um pacto civil.

Dessa forma, questionar o que era a literatura brasileira não parecia um problema relevante quando a ideia de nação, apesar de ter sido desde sempre um construto cultural, era tida como ponto pacífico dentro de um projeto político de consolidação de um território, que teve como ápice, no século xx, justamente o período de modernização mais intensa do país, com o qual colaboraram, como funcionários públicos, tanto críticos quanto escritores (Miceli, 2001). No entanto, na contemporaneidade, é difícil deixar de considerar que as fraturas sofridas pela categoria do nacional não atinjam também seus derivados, como uma "literatura nacional". Seria preciso uma atualização do estudo de Sérgio Miceli, apresentado em Intelectuais à brasileira, que identificava na formação de uma classe intelectual do país uma forte ligação com o Estado, que viabilizava o exercício do pensamento, com os prejuízos óbvios que tal comprometimento pode acarretar. Essa atualização

3 Sobre sistema literário ver Candido (2000, v. 1, p. 23). 
levaria em conta o fato de que hoje os escritores estão, em geral, afastados das funções burocráticas do Estado. ${ }^{4}$

Essas fraturas no conceito, não só como categoria teórica, mas também nas suas consequências nas práticas sociais, refletem-se muitas vezes no modo como os escritores encaram sua relação com o cânone nacional (este ainda firmemente sustentado pelo Estado via sistema educacional), com os demais autores contemporâneos e com o material de um real tensionado entre o local e o global.

A própria posição dos escritores está situada nessa tensão entre o localismo e o globalismo, ou internacionalismo, como prefere Pascale Casanova na sua análise geoeconômica do que ela chama de "república internacional das letras". Ao considerar o termo globalização neutralizador, por se tratar da compreensão da totalidade (CASANOVA, 2003, p. 6o), ela analisa o campo literário a partir das suas disputas internas e das disputas entre as literaturas nacionais. Para isso, desenvolve uma tese que sustenta que o "capital literário" é nacional. Ela relaciona o capital literário à língua em que determinada literatura é escrita e na sua relação histórica com o interesse dos Estados nacionais na constituição de uma literatura nacional que lhe servisse de estofo cultural. Para ela, então, a nação deve ser entendida de modo diferencial, isto é, nas suas características distintivas das demais nações, sendo, portanto, inter-nacional. Diferentemente, os Estados são relacionais, existindo na medida em que estabelecem relações com os demais Estados. Assim, para ela "língua e literatura foram ambas utilizadas como fundamentos da 'razão política'” (CASANOva, 2003, p. 53). Além disso, “as literaturas são portanto a emanação de uma identidade nacional, elas são construídas na rivalidade (sempre negada) e na luta literária, sempre internacionais" (CASANova, 2003, p. 55). Essa identificação entre Estado, nação e literatura, ainda que não desapareça, perde força na medida em que o campo literário ganha autonomia (Bourdieu, 1996). Ela usa como exemplo para essa independência justamente o caso dos escritores latino-americanos que ganham importância, com a geração do boom, na geopolítica literária internacional, o que não ocorre de modo equivalente no espaço político internacional (CASANOVA, 2003, p. 59).

4 Dentre as principais ocupações dos escritores levantados na pesquisa "Personagem do romance brasileiro contemporâneo" (DALCASTAGnè, 2005) estão a de jornalista e a de professor universitário. Assim, é menos comum a presença de escritores nos quadros da burocracia nacional. 
O patrimônio literário acumulado, como denomina Casanova, é o que também se denomina aqui de cânone. Ainda que se descole da política nacional, por se compor de obras reputadas como clássicos universais, esse cânone volta-se outra vez para a política interna, devido à apropriação que os Estados fazem dele, transformando-o num cânone nacional, um patrimônio da língua nacional.

No entanto, muito fica de fora dessa intercessão oficial entre o campo político e o campo literário, bem como, dentro da hierarquia interna desse campo literário, há uma infinidade de discursos que são mantidos nas suas margens. Se o conceito de "literatura brasileira" parece extremamente abrangente quando pensamos que inclui tudo aquilo que é escrito em português do Brasil e publicado dentro do mercado editorial nacional, ele não parece tão inclusivo quando consideramos o modo como o campo apresenta essa literatura, tanto na relação com os demais campos (político, econômico) da sociedade, quanto na esfera internacional. O capital literário brasileiro é baixíssimo na atual conjuntura do campo literário internacional. Nenhum dos dois escritores aqui discutidos, por exemplo, tem repercussão de peso fora do país (ainda que tenham sido traduzidos para outras línguas). O peso negativo da língua periférica impede que esses escritores despertem interesse internacional, e a geração do boom acabou por garantir espaço mais para a América Hispânica que para a América Latina como um todo.

O romance de Paulo Lins, no entanto, não se constrói nessa liminaridade que constitui o espaço de uma língua periférica. Cidade de Deus é um texto que pretende fazer parte de uma tradição, coroando, no final do século, um projeto literário. Assim, o romance se consagra pelas mãos da mesma crítica que construiu uma leitura de nação a partir das obras de Machado de Assis e de José de Alencar. À época do lançamento do livro, em 1997, tomou lugar uma ambiciosa estratégia de lançamento para o romance. Lançado em sua primeira edição como um romance extenso, o livro foi apresentado como um panorama da periferia carioca legítimo e literariamente qualificado. O crítico Roberto Schwarz, então disputando o posto de principal nome da crítica literária do campo literário brasileiro, ${ }^{5}$ apostou suas fichas no romance, empregando, como já destacado, seu método de análise tributário à escola modernista, embora revestido de uma orientação pós-colonialista, pela consciência da diferença

5 Sobre a estratégia de Schwarz no lançamento de Cidade de Deus, ver Miguel (1997). 
colonial expressa no seu projeto sobre Machado de Assis em Um mestre na periferia do capitalismo e Ao vencedor as batatas.

Com a consagração da narrativa de Lins, confirmada pela repercussão na academia e, posteriormente, via cinema, junto a um amplo público nacional e internacional, Schwarz também saiu vitorioso de sua aposta. A estratégia do crítico consiste em inserir Lins na série literária nacional. Seu artigo, cuja importância atribuída pelo crítica é comprovada por sua posterior republicação na coletânea Sequências Brasileiras, faz uma leitura dos movimentos internos à obra, mas não deixa de dar pistas de como o autor pode se integrar à literatura nacional. O gesto de Schwarz, conhecido por sua obra dedicada aos dois fundadores da chamada literatura brasileira Machado de Assis e José de Alencar -, acaba por incluir nesse inventário o neófito Paulo Lins.

O romance presta-se a essa leitura, uma vez que acaba por tratar com exotismo de cunho naturalista a fala e as práticas dos bandidos, num olhar que mescla, como Schwarz aponta, o científico e o literário. Esse procedimento de aproximação das ciências com a escrita literária, longe de um experimento de radicalidade discursiva,${ }^{6}$ foi um método caro à tradição realista-naturalista brasileira.

É inescapável aqui trazer o romance $O$ cortiço, de Aluísio Azevedo, para compreender o modo como Paulo Lins reedita seu método e linguagem em fins do século xx. Segundo Antonio Candido (2004), o romance de Azevedo trai a sua matriz francesa ao ser elaborado como uma alegoria do Brasil naquele fim de século XIX, extrapolando o recorte preciso que o naturalismo de Émile Zola utilizava como método para a recriação da realidade em sua literatura. Antes, porém, de chegar a obter essas imagens que abarcam tantos significados, o escritor tem de lidar com suas personagens, indivíduos ficcionais que, numa estética realista, têm sua representação ainda mais comprometida com a veracidade. É sabido que Azevedo fez pesquisas de campo antes de escrever seu romance, mas é notório a partir da leitura da obra que, em termos de elaboração literária de identidades, na maior parte dos casos, ele apenas colocou sobre fotografias já conhecidas as legendas que se esperava: mulatas sensuais, negras histéricas, gays

6 Entre os contemporâneos, Alberto Mussa, em O movimento pendular é quem se aproxima mais de uma radicalidade discursiva, que mescla inventário folclórico, crítica e ficção. 
feminilizados, negros violentos, enfim, a alteridade encerrada em tipos construídos a partir dos preconceitos da elite brasileira do final do século XIX.

No caso de romance de Lins, há tanto a pretensão de compreender de modo total um microcosmo que possibilite uma leitura alegórica, quanto a questão do método de pesquisa. Assim, há por um lado o observador in loco, que tanto é cientista quanto sujeito da experiência pesquisada, e por outro o recorte pretendido, que, no caso do romance de Lins, anuncia com precisão o de que ponto de vista, onde, quando e como que farão parte da construção de sua narrativa. Há a perspectiva de Busca-Pé, passando pela linguagem que o aproxima do épico, com direito à invocação à musa e à grandiloquência de um vocabulário rebuscado, até o preciso recorte histórico: do início da ocupação do espaço pelos assentados, em fins da década de 1960 e demarca como o tempo de seu desfecho o início da década de 1980.

Dessa forma, a adesão de Lins à série literária nacional é flagrante, persistindo, no entanto, nos movimentos da narrativa, a ideia do surgimento de um exercício policêntrico do poder na favela. Numa narrativa que traz para o primeiro plano a trajetória de um tirano de seu surgimento a sua queda o personagem Zé Miúdo -, é interessante notar como a dissolução desse poder concentrado num único sujeito nas mãos de um grupo parece apontar para o fim de uma era e de um modo de governo.

Por outro lado, a narrativa não investe em experimentos de linguagem. O romance se articula nos padrões de uma tradição. Essa tensão torna a obra de Lins tanto mais emblemática de uma crise imposta às grandes narrativas tradicionais, entre elas a de nação, que, na literatura, são obrigadas a encarar, no plano da diegese, a dissolução dessas certezas nas práticas sociais, mas que persistem nas formas discursivas escolhidas para narrar essa história. Cidade de Deus não deixa de ser uma aposta do campo ao mesmo tempo de renovação, no que se refere à autoria e à temática, e de conservação de um status quo, por meio das escolhas formais de Lins, que não perturbam a chamada "literatura brasileira".

"Literatura brasileira", no entanto, é uma categoria problemática, que merece maior aprofundamento por parte da crítica literária de modo a compreender esse qualificativo de nacionalidade em face da reconfiguração da própria noção de nação. 
Nesse sentido, um escritor de temário cosmopolita, como é o caso de Milton Hatoum, confronta, por meio de uma narrativa que oscila entre o tributo à tradição e o questionamento da relação dos sujeitos com as localidades às quais supostamente pertenceriam.

Stefania Chiarelli (2007, p. 54), ao analisar Relato de um certo oriente, aponta que Hatoum "enfatiza a tentativa de abertura da estrutura da narrativa tradicional". Na leitura de Chiarelli, a multivocidade do romance é uma tentativa de desestruturar o um olhar único sobre a narrativa, ou seja, é uma possibilidade de pluralizar as vozes e, assim, distribuir o poder do discurso. Em Dois irmãos, contudo, há um narrador apenas, e, nesse sentido, podemos enxergá-lo também como um narrador comprometido. O narrador, no caso, investiga sua paternidade, e, na condição de agregado na casa da família que protagoniza o romance, oferece um olhar ao mesmo tempo interno e externo. Assim, é um narrador comprometido com seus interesses e sua hermenêutica, à maneira da tradição canônica da literatura nacional, inaugurada com o Dom Casmurro, de Machado de Assis, evidenciando que a tradição tem papel importante no momento em que a literatura se volta para a discussão de qual é o seu lugar na geopolítica literária.

Em termos estruturais, dessa forma, Dois irmãos, encontra-se dentro da tradição do romanceiro nacional, como uma literatura que se autoquestiona, ainda que timidamente. Nesse sentido, o romance de Hatoum não se perde na autorreflexividade. Há ali o genuíno desejo de contar uma história. Hatoum, em entrevista à revista Estudos de literatura brasileira contemporânea concorda com tal afirmativa:

Não mordi a isca da inovação formal que significa apenas um exercício de estilo. [...] O mais importante não é perseguir a inovação a todo custo, e sim escrever o que de fato passou por uma experiência verdadeira (BARRETO et al., 2006, p. 143).

Isso se deve, talvez, ao fato de que há uma marcação identitária em jogo no romance de Hatoum. Como já foi discutido, ele inscreve uma comunidade imigrante no mapa da literatura brasileira sobre o Amazonas. Esse gesto de inclusão dá-se, sabemos, desde o surgimento do romance moderno, pela legitimação de uma história. A ascensão do romance deve-se a sua configuração como espaço de legitimação cultural de uma burguesia que ganhava poder no século XVIII, e, no projeto literário de Hatoum, essa lógica ainda reverbera. Isso ocorre também no romance de Paulo Lins, que pretende, 
antes de mais nada, contar uma história que escreva e legitime seu ponto de vista por meio do poder garantido ao discurso literário.

Hatoum também é marcado identitariamente, embora de modo mais dicreto que Lins. Sua diferença não está ligada à classe social ou grupo étnico (como no caso de Lins), mas como sujeito cuja identidade está ligada à imigração libanesa no Brasil. Não são poucas as análises que exploram esse viés, e, não se pode culpar os críticos, já que esse é um dos temas centrais das narrativas de Hatoum. Se Schwarz faz questão de destacar a posição étnico-social de Paulo Lins, não é comum ver a identidade étnico-social de Hatoum marcada. Embora sua origem árabe pudesse levar à discussão dessa diferença, Hatoum, intelectual de formação francesa, está conformado dentro do padrão do escritor nacional: homem, branco, professor universitário. Afirmo isso porque a etnicidade árabe, que em países como Estados Unidos, França e Alemanha, por exemplo, é uma diferença reforçada pelo racismo, num espaço como Manaus, em que as etnias indígenas estão mais evidentemente marcadas, é frequentemente apagada como branquidade. Assim, a inserção de Hatoum no campo literário dá-se de modo mais ou menos natural, com sua origem árabe sendo engolfada por sua posição de classe.

A ligação de Hatoum com o campo literário, como professor de literatura francesa, também lhe confere esse apagamento de sua identidade étnico nacional miscigenada. Seu domínio da linguagem literária é legitimado por seus títulos acadêmicos. Seu doutorado, curiosamente, é sobre Gustav Flaubert, escritor central na própria constituição da ideia de um campo literário (Bourdieu, 1996). Assim, habilitado a atuar como escritor, é desnecessário, na apresentação de seus romances, marcar seu lugar de fala como algo tão importante e carregado de valores como o de Paulo Lins.

$\mathrm{O}$ credenciamento de Hatoum como um autor identitariamente inscrito na tradição acaba por encontrar no seu estilo de escrita um paralelo, pois, a despeito da disrupções no modo como trata os sistemas sociais e de pensamento acerca das identidades nacionais no romance, o texto é mais preocupado em "contar uma história" do que investir numa radicalidade formal.

Os dois textos aqui discutidos são paradigmáticos de como parte da produção romanesca importante contemporânea - aquela consagrada pela crítica e pelo público - ainda retém, mesmo que nas suas estratégias narrativas 
ou de inserção no campo literário, a centralidade da questão do nacional e a preocupação em constituir-se como parte de uma série literária, e, em última instância de um sistema literário, do qual fazem parte outras obras que as precederam e às quais elas pagam tributo, como parte e fruto de uma acumulação. Emergindo a contrapelo da abordagem temática - cosmopolita ou microcósmica -, ou estruturalmente, por meio da conformação a uma literatura nacional e às suas formas consagradas, Cidade de Deus e Dois irmãos, pela importância que adquiriram são dois emblemas de que o século xIX e as relações mais diretas entre a nação e o romance estão vivos no campo literário brasileiro contemporâneo.

\section{Referências}

Albuquerque, Gabriel. Um autor, várias vozes: identidade, alteridade e poder na narrativa de Milton Hatoum. Estudos de Literatura Brasileira Contemporânea, Brasília, n. 28, p. 125-140, 2006.

Anderson, Benedict. Comunidades imaginadas. Tradução de Denise Bottman. São Paulo: Companhia das Letras, 2008.

Balakrisnhan, Gopal. Um mapa da questão nacional. Tradução de Vera Ribeiro. Rio de Janeiro: Contraponto, 2000.

BARreto, Francismar et al. Entrevista com Milton Hatoum. . Estudos de Literatura Brasileira Contemporânea, Brasília, n. 28, p. 141-47, 2006.

Bourdieu, Pierre. As regras da arte: gênese e estrutura do campo literário. Tradução de Maria Lúcia Machado. São Paulo: Companhia das Letras, 1996.

CAndido, Antonio. Formação da literatura brasileira: momentos decisivos. Belo Horizonte: Itatiaia, 2000. $2 \mathrm{v}$.

CAndido, Antonio. De cortiço a cortiço. In: CAndido, Antonio. O discurso e a cidade. São Paulo: Ouro Sobre Azul; Rio de Janeiro: Duas Cidades, 2004.

Carvalho, Bernardo. Teatro. São Paulo: Companhia das Letras, 1998.

Casanova, Pascale. República mundial das letras. Tradução de Marina Appenzzeler. São Paulo: Estação Liberdade, 2003.

Chiarelli, Stefania. Vidas em trânsito: as ficções de Samuel Rawet e Milton Hatoum. São Paulo: Annablume, 2007.

Dalcastagnè, Regina. A personagem do romance brasileiro contemporâneo: 1990-2004. Estudos de literatura brasileira contemporânea, Brasília, n. 26, p. 13-71, jul./dez. 2005.

EAgleton, Terry. Teoria da literatura: uma introdução. Tradução de Waltensir Dutra. São Paulo: Martins Fontes, 2003.

Hardt, Michael; Negri, Toni. Império. Tradução de Berilo Vargas. Rio de Janeiro: Record, 2004. Hatoum, Milton. Dois irmãos. São Paulo: Companhia das Letras, 2000.

Lins, Paulo. Cidade de Deus. 2. ed. São Paulo: Companhia das Letras, 2003. 
Mata, Anderson Luís Nunes da. As fraturas no projeto de uma literatura nacional: representação na narrativa brasileira contemporânea. Tese (Doutorado em Literatura) Universidade de Brasília, Brasília, $2010 a$.

MATA, Anderson Luís Nunes da. O silêncio das crianças: representações da infância na narrativa brasileira contemporânea. Londrina: Eduel, $2010 b$.

MatA, Anderson Luís Nunes da. À margem da BR: imagens do nacional no romance brasileiro contemporâneo. In: Dalcastagnè, Regina; MAtA, Anderson (Org.). Fora do retrato: estudos de literatura brasileira contemporânea. Vinhedo: Horizonte, 2012.

Melo, Adriana. Um jogo de espelhos: a representação metapoética na literatura na segunda metade do século xx. Revista Norteamentos, Sinop, v. 2, n. 3, p. 26-42, jan./jun. 2009. Disponível em: < http ://projetos.unemat-net.br/revista_norteamentos/arquivos/003/artigos/02.pdf>. Acesso em: 25 jan. 2010.

Miceli, Sérgio. Intelectuais à brasileira. São Paulo: Companhia das Letras, 2001.

Miguel, Luis Felipe. Um bicho solto em no campo literário. Boletim do Grupo de Estudos em Literatura Brasileira Contemporânea, n. 11, 1997.

Schwarz, Roberto. Cidade de Deus. In: Schwarz, Roberto. Sequências brasileiras. São Paulo: Companhia das Letras, 2001.

Shoнat, Ella; Stam, Robert. Crítica da imagem eurocêntrica. Tradução de Marcos Soares. São Paulo: CosacNaify, 2004.

Sommer, Doris. Ficções de fundação. Tradução de Glaucia Gonçalves e Eliana Reis. Belo Horizonte: Editora da UFMG, 2004.

Vigna, Elvira. Coisas que os homens não entendem. São Paulo: Companhia das Letras, 2002.

Recebido em 20 de fevereiro de 2017.

Aprovado em 6 de março de 2017.

\section{Resumo/Abstract/Resumen}

\section{Discursos do nacional no romance brasileiro contemporâneo: Dois irmãos e Cidade de Deus}

Anderson Luís Nunes da Mata

As relações entre as imagens do nacional e o romance brasileiro contemporâneo oscilam entre a crítica à tradição de fazer representar a nação na narrativa e a adesão a modelos estabelecidos no século xıx. O artigo discute como os romances Cidade de Deus, de Paulo Lins, e Dois irmãos, de Milton Hatoum, representam uma permanência da relação entre o romance e a representação da nação por meio de aspectos temáticos e formais.

Palavras-chave: representação, romance brasileiro contemporâneo, nação. 


\section{Discourses about the nation in contemporary brazilian novel: Two Brothers and City of God}

Anderson Luís Nunes da Mata

The links between the images of the nation and brazilian contemporary novels are either critical to the tradition of representing the nation in literature or subsumed to $19^{\text {th }}$ century models. This articles focuses on how City of God, by Paulo Lins, and Two Brothers, by Milton Hatoum, represent the resilience of the correspondence between the novel and the representation of the nation throughout formal and thematic aspects.

Keywords: representation, brazilian contemporary novel, nation

\section{Discursos de lo nacional en la novela brasileña contemporánea: Dos hermanos y Ciudad de Dios}

Anderson Luís Nunes da Mata

Las relaciones entre las imágenes de lo nacional y la novela brasileña contemporánea oscilan entre la crítica a la tradición de la representación de la nación y la adhesión a modelos del siglo XIX. El artículo se propone discutir como las novelas Ciudad de Dios, de Paulo Lins, y Dos Hermanos, de Milton Hatoum, representan la permanencia de la relación entre la novela y la representación de la nación a través de aspectos temáticos y formales.

Palabras clave: representación, novela brasileña contemporánea, nación. 